\title{
What parents don't know and how it may affect their children: Qualifying the disclosure-adjustment link
}

\author{
Tom Frijns*, Loes Keijsers, Susan Branje, Wim Meeus \\ Research Centre Adolescent Development, Utrecht University, Heidelberglaan 1, PO Box 80.140, 3508 TC, Utrecht, The Netherlands
}

Keywords:

Secrecy

Disclosure

Adolescent-parent relationship

Adolescent adjustment

\begin{abstract}
A B S T R A C T
Recent research has identified adolescent disclosure to parents as a powerful predictor of adolescent adjustment. We propose, however, that the common operationalization of adolescent disclosure incorporates the two separate constructs of disclosure and secrecy, and predicted that the disclosure-adjustment link can largely be explained by the unique contribution of secrecy from parents. A four-wave survey study among 309 adolescents tested these predictions. Factor analyses confirmed that disclosure and secrecy should be distinguished as two separate constructs. Moreover, in cross-lagged path analyses, only secrecy was a longitudinal predictor of adolescent internalizing (i.e., depression) and externalizing (i.e., delinquency) problems, disclosure was not. Secrecy consistently contributed to the longitudinal prediction of delinquency from early to middle adolescence, whereas it contributed to the prediction of depression only in early adolescence. Findings thus attest the importance of distinguishing between disclosure and secrecy and suggest that the disclosure-adjustment link may actually reflect a secrecy-maladjustment link.
\end{abstract}

(c) 2009 The Association for Professionals in Services for Adolescents. Published by Elsevier Ltd. All rights reserved.

\section{Introduction}

Recent research on parenting practices and adolescent adjustment has shown that it is important to consider the source of parental knowledge about their children because such knowledge comes not only from parental efforts like solicitation and control, but also from the child's voluntary disclosure of information (Kerr \& Stattin, 2000; Smetana, 2008; Stattin \& Kerr, 2000). In fact, adolescent disclosure was found to be the main source of parental knowledge. Moreover, it was the single most powerful predictor of adolescent adjustment. Adolescent disclosure has thus been identified as an important factor to study. At the same time, a recent interest in secrecy in adolescent-parent relationships has provided consistent evidence that keeping secrets from parents is associated with poor adjustment (e.g., Finkenauer, Engels, \& Meeus, 2002; Frijns, Finkenauer, Vermulst, \& Engels, 2005).

The present study will take a closer look at adolescent disclosure and its links with adjustment. Its objectives are twofold. First, we will argue that in the way it has frequently been operationalized in recent research, disclosure is confounded with secrecy and that the two are distinct constructs. The first aim of the present study is thus to examine whether disclosure and secrecy can be distinguished as two separate factors within a commonly used adolescent disclosure questionnaire. Second, we propose that secrecy makes a larger contribution to the disclosure-adjustment link than disclosure does. That is, we

\footnotetext{
* Corresponding author. Tel.: +31 (0)30 2531572; fax: +31 (0)30 2532352.

E-mail address: T.Frijns@uu.nl (T. Frijns).
} 
stipulate that the previously observed associations between disclosure and several forms of adolescent adjustment stem mainly from an association between secrecy and maladjustment. The second aim of the present study, therefore, is to investigate the predictive power of disclosure and secrecy regarding adolescent internalizing and externalizing problems.

\section{Adolescent disclosure}

Recent evidence suggests that adolescent disclosure is a stronger predictor of both parental knowledge and adolescent adjustment than parents' active efforts at monitoring their children (e.g., Keijsers, Branje, Van der Valk, \& Meeus, in press; Keijsers, Frijns, Branje, \& Meeus, in press; Kerr \& Stattin, 2000; Soenens, Vansteenkiste, Luyckx, \& Goossens, 2006; Stattin \& Kerr, 2000; Waizenhofer, Buchanan, \& Jackson-Newsom, 2004). This precedence of adolescent disclosure over parenting practices holds for internalizing problems like low self-esteem and depressed mood, as well as externalizing problems like delinquency. For instance, in contrast to findings on children's externalizing problems, most studies among adolescents did not find unique associations between parenting practices and adolescents' delinquency when controlling for adolescent disclosure, both concurrently (Kerr \& Stattin, 2000, 2003; Soenens et al., 2006; Stattin \& Kerr, 2000; Waizenhofer et al., 2004) and longitudinally (Keijsers, Branje, et al., in press; Keijsers, Frijns, et al., in press).

However, we will argue that the conclusion that adolescents' spontaneous disclosure of information predicts adjustment is a bit off. The adolescent disclosure measure that was developed by Stattin and Kerr (2000; Kerr \& Stattin, 2000) and used in subsequent studies (e.g., Keijsers, Branje, et al., in press; Keijsers, Frijns, et al., in press; Soenens et al., 2006) does not only address what adolescents freely disclose to their parents, but also what they actively conceal from their parents. Some items ask adolescents to rate the extent to which they disclose to their parents (e.g., "Do you spontaneously tell your parents about your friends (which friends you hang out with and how they think and feel about various things)?"), whereas other items ask them to rate the extent to which they keep secrets from their parents (e.g., "Do you keep a lot of secrets from your parents about what you do during your free time?"). To the extent that disclosure and secrecy can be construed as separate constructs, this measure could thus be said to confound disclosure with secrecy.

\section{Distinguishing between disclosure and secrecy}

Logic dictates that a piece of information that is kept secret is not disclosed, whereas a piece of information that is disclosed is not kept secret. It is not very surprising then, that disclosure and secrecy are often viewed as opposites and used interchangeably (e.g., Chelune, Waring, Vosk, Sultan, \& Odgen, 1984). However, disclosure and secrecy often occur simultaneously in everyday life. For example, when telling their parents about their school day, an adolescent may talk about some of the interesting topics that were discussed in class and the new friends they made. At the same time, they meticulously avoid making any reference to the ' $F$ ' they received in chemistry. Even when considering a specific piece of information, keeping this information secret from parents is different from not disclosing it. Mere non-disclosure is effortless, whereas keeping a secret requires a conscious decision to conceal information and can be hard work (Lane \& Wegner, 1995; Pennebaker, 1997). For instance, if the parents from our example were generally unconcerned with specific grades and more focused on their child's happiness, the adolescent might still not have mentioned the low grade because they were too enthusiastic about sharing the news of their newfound friends. This non-disclosure would be very different from the active concealment of the bad grade, which would involve careful monitoring of the conversation, thought suppression and diversionary tactics. Reflecting this distinction, secrecy has also been called "active inhibition of disclosure" (Pennebaker, 1989). Thus, although disclosure and secrecy are clearly related aspects of adolescent-parent communication, their divergent qualities also set them apart as two distinct phenomena (for similar arguments, see Finkenauer \& Hazam, 2000; Larson \& Chastain, 1990; but see also Kahn \& Hessling, 2001).

\section{Qualifying the disclosure-adjustment link}

Although it has been established that adolescent disclosure is associated with improved adjustment, it remains unclear exactly why this link exists. Perhaps adolescent disclosure enables parents to more effectively offer support and to address their child's needs. Alternatively, there may be intrapersonal reasons for the link between disclosure and adjustment. For instance, adolescents of an open and disclosing disposition may be less vulnerable to negative outcomes or less prone to deviant behaviors. Finally, the positive link between adolescent disclosure to parents and adjustment may reflect the positive effects of confiding personal experiences to others (e.g., Buhrmester \& Prager, 1995; Pennebaker, 1990; Pennebaker, Zech, \& Rimé, 2001). The benefits of such disclosure have been shown in an abundance of research and include improved physical health (Pennebaker, Colder, \& Sharp, 1990; Petrie, Booth, Pennebaker, Davison, \& Thomas, 1995) and psychological well-being (Francis \& Pennebaker, 1992; Greenberg, Wortman, \& Stone, 1996; for a review see Smyth, 1998).

We propose that the advantages of disclosure should actually be construed as the disadvantages of secrecy. Secrecy has been proposed to produce a number of drawbacks because it is an effortful process. It requires constant active monitoring and inhibition or suppression of one's thoughts, feelings, and behavior to avoid revelation. This continued active inhibition and thought suppression are suggested to serve as cumulative stressors that increase the probability of stress-related psychological problems, prevent full processing of the secret information, and cause mental rumination and obsessive preoccupation with the secret (Lane \& Wegner, 1995; Pennebaker, 1989, 1997), which may ultimately cause psychopathology (Newth \& 
Rachman, 2001; Wegner \& Lane, 1995). There are additional reasons why secrecy may be linked to externalizing maladjustment in adolescence. When adolescents keep secrets from their parents to avoid punishment or criticism (Guerrero \& Afifi, 1995; Marshall, Tilton-Weaver, \& Bosdet, 2005), they may develop a sense of being able to get away with misconduct. As long as their concealment is successful, this idea will not be discredited and parents are robbed of the chance to steer their children away from deviance, increasing the likelihood of further mischievous and delinquent acts. Empirical investigations of the consequences of secrecy have focused mostly on adults and have linked secrecy with a variety of detriments, including physical complaints, anxiety, stress, loneliness and depression (e.g. Finkenauer \& Rimé, 1998a; Ichiyama et al., 1993; Kelly \& Achter, 1995; Lane \& Wegner, 1995; Larson \& Chastain, 1990; Pennebaker \& Susman, 1988).

Research among adolescents suggests that the disadvantages of secret-keeping that have been found among adults, hold in adolescence (e.g., Finkenauer et al., 2002; Finkenauer, Engels, \& Kubacka, 2008; Frijns \& Finkenauer, 2009; Frijns et al., 2005; Smetana, Metzger, Gettman, \& Campione-Barr, 2006). Studies that focused on secrecy from parents have shown that it is concurrently and longitudinally associated with both internalizing and externalizing problem behaviors (Finkenauer et al., 2002; Frijns et al., 2005). In support of our assertion that secrecy is the main driving force behind the disclosure-adjustment link, Finkenauer et al.'s (2002) cross-sectional study yielded disadvantages of keeping secrets from parents while controlling for disclosure to parents, but no advantages of disclosure while controlling for secrecy. In the present study, we will longitudinally examine the associations of disclosure and secrecy with adolescent adjustment.

\section{The present research}

To investigate the associations of disclosure to and secrecy from parents with adolescent adjustment, we used data from 309 adolescents over four consecutive measurement waves of an ongoing longitudinal study. We predicted that disclosure and secrecy can be distinguished as two distinct factors of adolescent information management in their relationship with their parents. Furthermore, we predicted that, when pitted against each other, secrecy from parents would be more strongly associated longitudinally with adolescents' internalizing and externalizing problems than disclosure to parents. Although this hypothesis concerns the prediction of problem behavior by disclosure and secrecy, we will examine bidirectionality in the links between adolescent information management and adjustment as it seems reasonable to assume that troubled adolescents will have more reason to conceal information and to disclose less to their parents. Specifically, we will examine the longitudinal associations of disclosure and secrecy with delinquency and depression over 4 consecutive years (see Fig. 1 ).

\section{Method}

\section{Sample characteristics}

Data for the current study came from a subsample of an ongoing longitudinal study on relationships in adolescence, named CONflict And Management Of RElationships (CONAMORE) (Meeus et al., 2004), in which 938 Dutch adolescents have currently participated in annual assessments at their schools for 5 consecutive years. Of the 656 Dutch two-parent families who were invited to participate in additional annual home-visits, 401 accepted our invitation, and 323 were randomly selected for financial reasons. At the start of the home-visits, 1 year after the selection, 309 families were still two-parent families.

The current study uses data collected from the adolescents of these 309 families at four consecutive measurement waves. At Time 1 (T1), adolescents' mean age was 13.2 years $(\mathrm{SD}=0.51)$. The 149 boys and 160 girls came from various high schools located in municipalities in an urban area in The Netherlands and were in grade 2 of junior high. Adolescents represented different educational tracks, with approximately 37\% preparing for university, 51\% preparing for higher professional education, and $12 \%$ preparing for blue-collar work. Of the fathers, $1 \%$ did not finish high school, $24 \%$ graduated from high school, 39\% graduated from middle or higher level vocational/technical training, and 34\% had a university degree. Of the

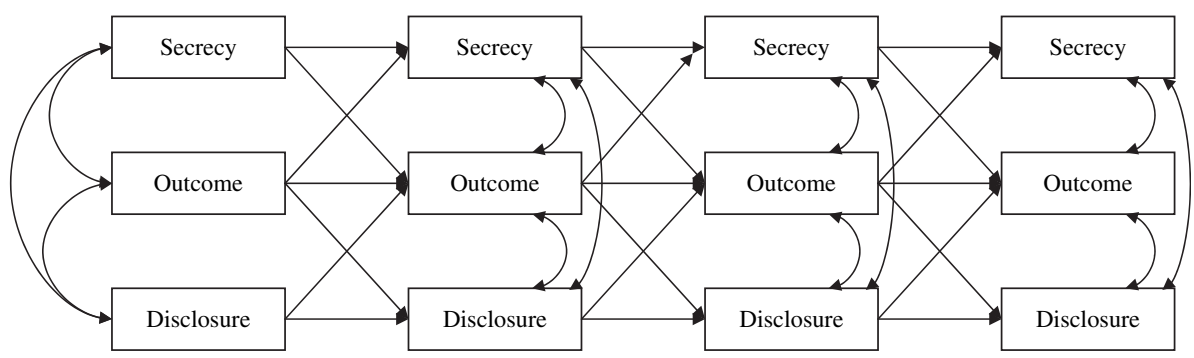

Fig. 1. Longitudinal cross-lagged path model. Note. Two- and three-year stability paths were included in the model but are not displayed. 
mothers, $1 \%$ did not finish high school, 36\% graduated from high school, $43 \%$ graduated from middle or higher vocational/ technical training, and $19 \%$ had a university degree. A large majority of fathers (87\%) and a minority of mothers (10\%) worked more than $32 \mathrm{~h}$ a week, and $62 \%$ of mothers worked at least $8 \mathrm{~h}$ a week. Thirteen families became single-parent families during the research project.

We compared the sample $(n=309)$ with the Dutch two-parent families $(n=347)$ from the larger sample that were not participating in home-visits. A two-tailed $t$ test showed no differences in the age of adolescents $(t(645)=-1.88, p=0.06)$, and a chi-square test revealed no differences in gender composition $\left(\chi^{2}(1, N=656)=0.74, p=0.39\right)$. Furthermore, two-tailed $t$ tests showed no differences in adolescents' mean scores on depression $(t(642)=0.83, p=0.41)$ and delinquency $(t(643)=-1.82, p=0.07)$ at $\mathrm{T} 1$.

\section{Procedure}

Before the study, adolescents and their parents received written information about the study and provided written informed consent. Adolescents participated annually in two assessments: school visits after school hours and home-visits in which parents also participated. Trained research assistants provided verbal instructions in addition to the written instructions that accompanied the large battery of questionnaires. Families received the equivalent of US $\$ 35$ per home-visit and adolescents received the equivalent of US \$ 13 per school-assessment. Only the measures that are relevant to the current study will be described here.

\section{Questionnaires}

\section{Adolescent disclosure and secrecy}

The extent to which adolescents freely divulge information to their parents and the extent to which they conceal information from their parents were assessed during four annual home-visits using items from the Adolescent disclosure scale developed by Kerr and Stattin (2000; Stattin \& Kerr, 2000). Three items measured adolescents' voluntary and spontaneous disclosure to their parents about friends, activities and whereabouts: (1) 'Do you talk at home about how you are doing in the different subjects at school?', (2) ‘Do you spontaneously tell your parents about your friends (which friends you hang out with and how they think and feel about various things)?', and (3) 'Do you usually tell how school was when you get home (how you did on different exams; your relationship with teachers)?'. Two items measured adolescents' secrecy from their parents: (4) 'Do you keep a lot of secrets from your parents about what you do during your free time?' and (5) 'Do you hide a lot from your parents about what you do during nights and weekends?' Questions about adolescent disclosure and secrecy were rated by adolescents on a 5-point Likert scale, ranging from 1 (never) to 5 (often). At T1-T3, all adolescents reported on both their parents. At T4, part of the adolescent sample reported on fathers and mothers separately and for these 239 adolescents we computed combined mean scores of their reports on their father and mother. ${ }^{1}$ Across waves, reliabilities ranged from $\alpha=0.68$ to $\alpha=0.83$ for the three-item adolescent disclosure scale, and from $\alpha=0.71$ to $\alpha=0.81$ for the entire five-item scale. The correlation between the secrecy items ranged from $r=0.47$ to $r=0.62$. The correlation between the secrecy and the disclosure scale ranged from $r=-0.29$ to $r=-0.47$ across waves.

\section{Outcome measures}

During four annual school visits, adolescents reported on their psychosocial well-being. To assess adolescent symptoms of depression we made use of the Children's Depression Inventory (CDI) (Craighead, Smucker, Craighead, \& Ilardi, 1998). This selfreport scale comprises 27 items, such as "I am sad all the time", "I do everything wrong" and "I will never end up all right". Items were scored on 3-point Likert scales ( 1 =false, 2 =somewhat true, $3=$ very true). Reliability of this scale ranged from $\alpha=0.86$ to $\alpha=0.89$ across waves. Adolescent delinquency was assessed with a self-report questionnaire of 16 items on minor delinquency (adjusted from Baerveldt, Rossem van, \& Vermande, 2003). Respondents indicated on a 4-point scale (1 =never, $2=$ once, 3 =two or three times, and $4=$ four times or more) how many times they had committed minor offences, such as shoplifting, petty theft, and vandalism in the previous year. Reliabilities of this scale were between $\alpha=0.82$ and $\alpha=0.84$.

\section{Data considerations and analyses}

Over the four measurement waves of our study, $87.7 \%$ of the respondents had no missing values, and a maximum of $3.6 \%$ of the cases was missing per variable. We tested our predictions by conducting confirmatory factor analyses and cross-lagged path analyses on our data in Mplus (Muthen \& Muthen, 2006). Models were estimated with a Robust Maximum Likelihood estimation method (Satorra \& Bentler, 1994), which is a better way to estimate standard errors when normality assumptions are violated. Because missing data were completely at random in Little's (1988) (see also Little \& Rubin, 2002) MCAR test: $\chi^{2}$

\footnotetext{
1 The average combined scores of adolescents' reports on fathers and mothers did not differ from the scores of the 79 adolescents who reported on both parents, for disclosure $(t(298)=0.60, p=0.55)$ nor secrecy $(t(299)=1.70, p=0.09)$. Moreover, adolescents' reports of disclosure to fathers and mothers were highly correlated $(r=0.64, p<0.001)$, as were their reports of secrecy from fathers and mothers $(r=0.69, p<0.001)$. Finally, the correlations of secrecy and disclosure with depression and delinquency did not differ between fathers and mothers (all Fisher's $r$ to $z<0.7, p>0.24$ ).
} 
$(506, N=292)=541.21, p=0.14)$, respondents with missing data were included in model estimations (using the Full Information Maximum Likelihood option in Mplus) (cf. Enders \& Bandalos, 2001).

\section{Results}

\section{Factor analyses}

We conducted preliminary exploratory factor analyses on the adolescent disclosure items at each wave and consistently found two well-defined factors underlying the data, explaining 70-74\% of the variance in the initial values (see Table 1 for descriptive statistics on item level at T1). Thus assured of the plausibility of our proposed two-factor structure, we proceeded to test our prediction that a two-factor model would fit the data better than a one-factor solution by conducting confirmatory factor analyses on our data at T1 in Mplus. We compared a one-factor solution with a two-factor solution in which three disclosure items loaded on the first factor and the two secrecy items loaded on the second factor (see Fig. 2 for the models and their results). As can clearly be seen, only the two-factor model had a good model fit, and model comparisons based on the BIC confirmed the superiority of the two-factor model. Factor loadings for both the disclosure and secrecy items were well above 0.45 and can thus be considered good (Tabachnick \& Fidell, 2001, p. 625). To ensure the reliability of the second factor with only two items, we checked that these items were highly correlated with one another and relatively uncorrelated with all other items (see Table 1; Tabachnick \& Fidell, 2001). As can be seen, the two factors were moderately correlated $(r=-0.38$, $p<0.001$ ). These analyses were repeated for each of the three following waves. We consistently found that the two-factor structure represented the data better than the one-factor solution.

To assess the consistency and comparability of the factor structure across waves, we tested the factorial invariance over time by conducting a longitudinal factor analysis in which all factor loadings were first estimated freely and then constrained to be equal at all waves. Thus, we first estimated an unconstrained model that included four two-factor structures (one at each wave) without correlations among the waves. We then estimated a model in which the factor loadings of the disclosure items on the first factor and the secrecy items on the second factor were constrained to be equal across the four waves. Finally, we compared the fit of these two models and found that adding the constraints did not worsen the model fit $\left(\Delta \chi^{2}=15.25, d f=9\right.$, $p=0.08$; Satorra \& Bentler, 2001), which confirms the equivalence of the factorial models at each wave. Taken together, these results confirm that adolescent disclosure and secrecy are related but distinct constructs across the four waves of this study.

\section{The predictive power of disclosure and secrecy}

To assess the longitudinal associations between disclosure, secrecy and adolescent adjustment, we analyzed two fourwave longitudinal cross-lagged models linking disclosure and secrecy to delinquency and depression, respectively (see Fig. 1; descriptives and correlations among these variables can be found in Table 2). These models included (1) correlations between all variables at each wave, (2) stability paths for each of the variables, and (3) cross-lagged paths from disclosure and secrecy to the outcome and vice versa in each interval. We tested our prediction that disclosure and secrecy should be differentially related to adolescent adjustment by constraining the cross-paths from secrecy and disclosure to the outcome measure to be equal (to do so, we reverse coded the disclosure items to match the direction of the secrecy items). A significant increase in chi-square would indicate that secrecy and disclosure predict the outcome measure differentially.

In the model for delinquency, all variables were concurrently related in the expected directions at T1, and all were relatively stable over the waves (see Table 3 ). Secrecy longitudinally predicted delinquency across all intervals ( $\beta$ 's between 0.08 and 0.18) while disclosure did not predict delinquency. Over the three intervals, this difference in cross-paths from secrecy versus disclosure to delinquency was significant $\left(\Delta \chi^{2}=14.77, d f=3, p<0.01\right)$, with secrecy predicting delinquency more strongly than disclosure did. Delinquency was a predictor of secrecy over the first $(\beta=0.18)$ and third interval $(\beta=0.11)$, but did not predict disclosure over any of the intervals. Testing the three cross-paths from delinquency to secrecy against the cross-paths from delinquency to disclosure, we found that delinquency was a stronger predictor of secrecy than of disclosure

\section{Table 1}

Descriptives and correlations among adolescent disclosure and secrecy items at T1.

\begin{tabular}{|c|c|c|c|c|c|c|}
\hline \multirow[t]{2}{*}{ item } & \multicolumn{2}{|c|}{ Descriptives } & \multicolumn{4}{|c|}{ Correlations } \\
\hline & Mean & SD & Item 1 & Item 2 & Item 3 & Item 4 \\
\hline Item 1 (D): ‘Do you talk at home about how you are doing in the different subjects at school?’ & 3.72 & 0.76 & & & & \\
\hline $\begin{array}{l}\text { Item } 2 \text { (D): 'Do you spontaneously tell your parents about your friends (which friends you } \\
\text { hang out with and how they think and feel about various things)?' }\end{array}$ & 3.41 & 0.92 & $0.51^{* * *}$ & & & \\
\hline $\begin{array}{l}\text { Item } 3 \text { (D): 'Do you usually tell how school was when you get home (how you did on different } \\
\text { exams; your relationship with teachers)?' }\end{array}$ & 3.83 & 0.87 & $0.46^{* * *}$ & $0.46^{* * *}$ & & \\
\hline Item 4 (S): 'Do you keep a lot of secrets from your parents about what you do during your free time?' & 1.88 & 0.78 & $-0.19^{* *}$ & $-0.18^{* *}$ & $-0.28^{* * *}$ & \\
\hline Item 5 (S): 'Do you hide a lot from your parents about what you do during nights and weekends?' & 1.55 & 0.73 & $-0.17^{* *}$ & $-0.18^{* *}$ & $-0.25^{* * *}$ & $0.62^{* * *}$ \\
\hline
\end{tabular}

Note. $\mathrm{D}=$ Item referring to disclosure; $\mathrm{S}=$ Item referring to secrecy; ${ }^{* *} p<0.01,{ }^{* * *} p<0.001$. 


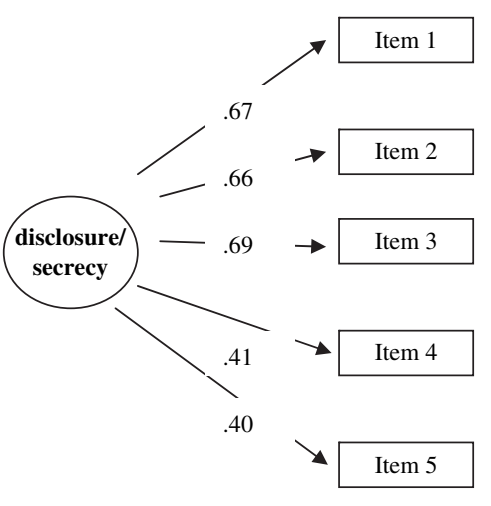

Fit:

$\mathrm{X}^{2}(5)=127.36 ; \mathrm{TLI}=.33 ; \mathrm{RMSEA}=.28$

$\mathrm{BIC}=3528.88$

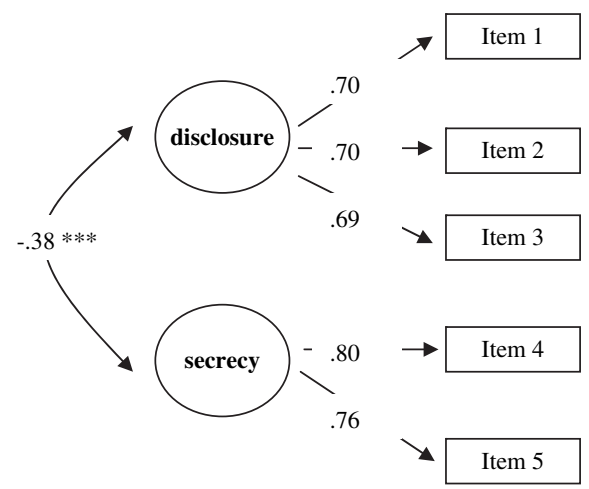

Fit:

$\mathrm{X}^{2}(4)=6.29 ; \mathrm{TLI}=.98 ; \mathrm{RMSEA}=.04$

$\mathrm{BIC}=3413.52$

Fig. 2. Confirmatory factor analyses for the one- and two-factor models at T1.

$\left(\Delta \chi^{2}=10.23, d f=3, p=0.02\right)$. Thus, we found that secrecy and delinquency were reciprocally related over time, whereas no relation was found between disclosure and delinquency while controlling for secrecy.

In the model for depression, all variables were again concurrently related in the expected directions at $\mathrm{T} 1$, and all were relatively stable over the waves (see Table 4). Disclosure was not a significant longitudinal predictor of depression. Secrecy, on the other hand, predicted depression, but only over the first interval $(\beta=0.19)$. Secrecy was thus found to be a stronger predictor of depression in early adolescence than disclosure was $\left(\Delta \chi^{2}=9.10, d f=3, p=0.03\right)$. Depression did not predict secrecy longitudinally, and although it significantly predicted disclosure in the first interval only $(\beta=0.16)$, there were no overall differences in its prediction of secrecy versus disclosure $\left(\Delta \chi^{2}=1.15, d f=3, p=0.77\right)$. We thus found that secrecy predicted depression in early adolescence, whereas depression did not predict disclosure or secrecy differentially.

Taken together, we found that the adolescent disclosure measure was better described by a two-factor structure distinguishing between disclosure and secrecy than by a one-factor structure. Moreover, secrecy was bidirectionally linked with delinquency from early to middle adolescence and predicted depression in early adolescence, whereas disclosure did not predict these problems, which further underscores the external validity of the two-factor solution.

\section{Discussion}

The present research revisited the disclosure-adjustment link that has repeatedly been found in research on parenting practices and adolescent-parent communication. To our knowledge, it is the first study to examine whether disclosure and secrecy (1) can be distinguished as two separate factors within a commonly used adolescent disclosure measure and (2) are differentially longitudinally related to externalizing and internalizing problems in adolescence. Its results can be summarized as follows. In both exploratory and confirmatory factor analyses, and across four consecutive measurement waves, our proposed two-factor structure of the adolescent disclosure measure consistently emerged as the optimal solution. Furthermore, the factor structure was invariant over time, indicating that the meaning of the two factors was comparable across the four waves. Thus, disclosure and secrecy should be distinguished as two separate but related factors in adolescent information management. Path analyses clearly consolidated the external validity of our proposed distinction between disclosure and secrecy by showing that the two are differentially related to measures of externalizing and internalizing problems.

Table 2

Descriptives and correlations among the study variables at T1.

\begin{tabular}{lllll}
\hline Variable & Descriptives & & \multicolumn{2}{c}{ Correlations } \\
\cline { 2 - 3 } & Mean & SD & & 1. \\
\hline 1. Disclosure & 3.65 & 0.69 & & \\
2. Secrecy & 1.72 & 0.68 & $-0.29^{* * *}$ \\
3. Depression & 1.16 & 0.20 & $-0.12^{*}$ & $0.25^{* * *}$ \\
4. Delinquency & 1.10 & 0.21 & $-0.19^{* *}$ & $0.29^{* * *}$ \\
\hline
\end{tabular}

Note. ${ }^{*} p<0.05,{ }^{* *} p<0.01,{ }^{* * *} p<0.001$. 
Table 3

Parameter estimates of the cross-lagged model for delinquency (unconstrained)

\begin{tabular}{|c|c|c|c|c|c|c|c|c|c|}
\hline \multirow[t]{2}{*}{ Parameter estimate } & \multicolumn{3}{|c|}{ Time $1-2(\mathrm{~T} 2)$} & \multicolumn{3}{|c|}{ Time $2-3(\mathrm{~T} 3)$} & \multicolumn{3}{|c|}{ Time $3-4(\mathrm{~T} 4)$} \\
\hline & $B$ & SE & $\beta$ & $B$ & SE & $\beta$ & $B$ & SE & $\beta$ \\
\hline \multicolumn{10}{|l|}{ T1 associations } \\
\hline Disclosure and delinquency & -0.03 & 0.01 & $-0.21^{* * *}$ & & & & & & \\
\hline Secrecy and delinquency & 0.05 & 0.01 & $0.32^{* *}$ & & & & & & \\
\hline Disclosure and secrecy & -0.14 & 0.03 & $-0.29 * * *$ & & & & & & \\
\hline \multicolumn{10}{|l|}{ Stability paths } \\
\hline Disclosure & 0.42 & 0.07 & $0.45^{* * *}$ & 0.52 & 0.06 & $0.50^{* * *}$ & 0.44 & 0.06 & $0.40^{* * *}$ \\
\hline Secrecy & 0.43 & 0.08 & $0.40^{* * *}$ & 0.45 & 0.05 & $0.48^{* * *}$ & 0.34 & 0.06 & $0.31^{* * *}$ \\
\hline Delinquency & 0.75 & 0.13 & $0.66^{* * *}$ & 0.56 & 0.10 & $0.51^{* * *}$ & 0.65 & 0.13 & $0.62^{* * *}$ \\
\hline \multicolumn{10}{|l|}{ Cross-lagged paths } \\
\hline Disclosure $\rightarrow$ delinquency & 0.01 & 0.01 & 0.01 & -0.01 & 0.02 & -0.03 & -0.02 & 0.02 & -0.04 \\
\hline Secrecy $\rightarrow$ delinquency & 0.04 & 0.02 & $0.12^{*}$ & 0.03 & 0.01 & $0.08^{*}$ & 0.07 & 0.02 & $0.18^{* * *}$ \\
\hline Delinquency $\rightarrow$ disclosure & -0.03 & 0.14 & -0.01 & -0.24 & 0.13 & -0.08 & 0.00 & 0.12 & 0.00 \\
\hline Delinquency $\rightarrow$ secrecy & 0.61 & 0.28 & $0.18^{*}$ & 0.10 & 0.15 & 0.04 & 0.31 & 0.11 & $0.11^{* *}$ \\
\hline \multicolumn{10}{|l|}{ Correlated change } \\
\hline Disclosure and delinquency & -0.01 & 0.01 & $-0.08^{*}$ & -0.01 & 0.01 & -0.06 & -0.01 & 0.01 & -0.04 \\
\hline Secrecy and delinquency & 0.03 & 0.01 & $0.16^{* *}$ & 0.01 & 0.01 & 0.08 & 0.02 & 0.01 & $0.07^{* *}$ \\
\hline Disclosure and secrecy & -0.08 & 0.02 & $-0.17^{* * *}$ & -0.07 & 0.02 & $-0.15^{* * *}$ & -0.13 & 0.03 & $-0.24^{* * *}$ \\
\hline Model fit (CFI; TLI; RMSEA) & 0.98 & 0.94 & 0.06 & & & & & & \\
\hline
\end{tabular}

Note. Two-and 3-year stability paths were included in the model but are not displayed.

Specifically, we found that secrecy, but not disclosure, was a longitudinal predictor of depression and delinquency. These findings clearly suggest that secrecy is the driving force behind the disclosure-adjustment link, which may thus be more accurately described as a secrecy-maladjustment link.

Secrecy from parents was bidirectionally linked to delinquency from early to middle adolescence. Thus, secrecy consistently contributed to the longitudinal prediction of delinquency, but delinquency also contributed to secrecy from parents. This finding may not seem very surprising when one considers the content of the problem behavior. Delinquent acts are prime candidates for secrecy because such acts are generally frowned upon by parents, and adolescents may seek to avoid punishment or criticism (Guerrero \& Afifi, 1995; Marshall et al., 2005). As mentioned before, keeping these acts secret increases the likelihood of further delinquent behavior, which provides adolescents with even more things to keep secret. In this way, secrecy and delinquency reinforce each other.

In contrast to the findings on delinquency, secrecy from parents contributed to the prediction of depression only in early adolescence, and depression did not contribute to the prediction of secrecy. Our findings were thus more consistent for delinquency than for depression. Perhaps secrecy from parents leads to depression only in early adolescence because parents are the

Table 4

Parameter estimates of the cross-lagged model for depression (unconstrained).

\begin{tabular}{|c|c|c|c|c|c|c|c|c|c|}
\hline \multirow[t]{2}{*}{ Parameter estimate } & \multicolumn{3}{|c|}{ Time $1-2(\mathrm{~T} 2)$} & \multicolumn{3}{|c|}{ Time $2-3$ (T3) } & \multicolumn{3}{|c|}{ Time $3-4(\mathrm{~T} 4)$} \\
\hline & $B$ & SE & $\beta$ & $B$ & SE & $\beta$ & $B$ & SE & $\beta$ \\
\hline \multicolumn{10}{|l|}{ T1 associations } \\
\hline Disclosure and depression & -0.02 & 0.01 & $-0.16^{*}$ & & & & & & \\
\hline Secrecy and depression & 0.04 & 0.01 & $0.28^{* * *}$ & & & & & & \\
\hline Disclosure and secrecy & -0.14 & 0.03 & $-0.29^{* * *}$ & & & & & & \\
\hline \multicolumn{10}{|l|}{ Stability paths } \\
\hline Disclosure & 0.40 & 0.06 & $0.42^{* * *}$ & 0.54 & 0.06 & $0.51^{* * *}$ & 0.44 & 0.06 & $0.40^{* * *}$ \\
\hline Secrecy & 0.47 & 0.08 & $0.43^{* * *}$ & 0.45 & 0.05 & $0.49^{* * *}$ & 0.36 & 0.06 & $0.34^{* * *}$ \\
\hline Depression & 0.48 & 0.09 & $0.48^{* * *}$ & 0.57 & 0.07 & $0.55^{* * *}$ & 0.31 & 0.08 & $0.36^{* * *}$ \\
\hline \multicolumn{10}{|l|}{ Cross-lagged paths } \\
\hline Disclosure $\rightarrow$ depression & 0.01 & 0.01 & 0.04 & -0.01 & 0.02 & -0.04 & -0.01 & 0.01 & -0.02 \\
\hline Secrecy $\rightarrow$ depression & 0.06 & 0.02 & $0.19^{* *}$ & 0.02 & 0.02 & 0.08 & -0.02 & 0.01 & -0.06 \\
\hline Depression $\rightarrow$ disclosure & -0.49 & 0.18 & $-0.16^{* *}$ & 0.19 & 0.15 & 0.06 & 0.19 & 0.16 & 0.06 \\
\hline Depression $\rightarrow$ secrecy & 0.36 & 0.23 & 0.10 & -0.06 & 0.17 & -0.02 & -0.01 & 0.17 & 0.00 \\
\hline \multicolumn{10}{|l|}{ Correlated change } \\
\hline Disclosure and depression & -0.01 & 0.01 & -0.04 & -0.01 & 0.01 & -0.05 & 0.00 & 0.01 & -0.03 \\
\hline Secrecy and depression & 0.02 & 0.01 & $0.11^{*}$ & 0.01 & 0.01 & 0.05 & 0.00 & 0.01 & 0.01 \\
\hline Disclosure and secrecy & -0.08 & 0.02 & $-0.16^{* * *}$ & -0.07 & 0.02 & $-0.14^{* * *}$ & -0.13 & 0.03 & $-0.24^{* * *}$ \\
\hline Model fit (CFI; TLI; RMSEA) & 0.97 & 0.93 & 0.06 & & & & & & \\
\hline
\end{tabular}

Note. Two- and 3-year stability paths were included in the model but are not displayed. 
prime relational partners. As relationships outside the family gain importance over the course of adolescence (e.g., Cotterell,1996), friends become available to confide secrets to (Buhrmester, 1990; Buhrmester \& Prager, 1995; Hartup, 1996), which may benefit adolescents' adjustment and reduce the effects of secrecy from parents (cf. Hartup, 1996; Masten \& Coatsworth, 1998). At the same time, increases in the amount of time spent in leisure time activities with friends provide opportunity for engagement in deviant behavior that may be easier and more tempting to conceal because it occurs outside of the family context, thus enabling the continued mutual reinforcement of secrecy and delinquency. The fact that, unlike delinquency, depression did not longitudinally predict secrecy may be the result of anticipated parental reactions. Adolescents may expect positive, supportive parental reactions to revelation of depressive feelings, whereas they will likely expect confessions of misconduct to be met with disapproval and punishment (cf. Marshall et al., 2005; Smetana, Villalobos, Rogge, Tasopoulos-Chan, 2010).

Our findings corroborate previous arguments and findings that disclosure and secrecy can and should be distinguished as two separate but related factors in adolescent-parent information management (e.g., Finkenauer et al., 2002; Finkenauer, Frijns, Engels, \& Kerkhof, 2005; Smetana et al., 2006). Similarly, we found that when disclosure and secrecy are entered together in a single analysis, only secrecy predicts adolescent adjustment. This finding is a longitudinal replication of previous cross-sectional findings (Finkenauer et al., 2002). Our study does not, however, provide evidence as to why the predictive power of secrecy is greater than that of disclosure. We will propose four explanations of the precedence of secrecy in predicting adolescent adjustment based on some of its characteristics.

First, unlike disclosure, secrecy is commonly viewed as something negative and is associated with "having something to hide": something shameful or bad that is negatively appraised by the secret-keeper or society at large (e.g., Bok, 1989; Finkenauer \& Rimé, 1998b). As such, our results could be construed as another manifestation of the general phenomenon that negatively valenced events (in this case keeping secrets from parents) tend to have a greater impact on individuals than positively valenced events of the same type (disclosing information to parents) (Baumeister, Bratslavsky, Finkenauer, \& Vohs, 2001).

A second explanation that has been mentioned previously is that secrecy, in contrast to mere non-disclosure, is an active endeavor that requires constant active monitoring and inhibition or suppression of one's thoughts, feelings, and behavior to avoid revelation of secret information. All this hard work may wear and tear mind and body, causing physiological arousal and psychological stress that lead to maladjustment (e.g., Lane \& Wegner, 1995; Pennebaker, 1989).

A third explanation that has already been touched upon is that keeping secrets means that adolescents are never exposed to their parents' perspective, wrath, support or guidance. This may result in a closed system of secret-related thoughts and distorted perceptions that are never challenged, which could lead to increased internalizing and externalizing problems.

Finally, secrecy from parents involves a conscious decision to conceal information from important relational partners. Thus, unlike spontaneous disclosures about daily affairs, this information is not likely to be trivial. Although the items concerning disclosure and secrecy in Stattin and Kerr's (2000; Kerr \& Stattin, 2000) disclosure measure both refer to everyday mundane events, the questions about keeping secrets may yield information that is regarded as more important than questions about disclosure because secrecy, by nature, implies events or experiences that were important enough to be consciously and actively concealed. This difference in the experience of secret versus disclosed information may help to explain why keeping secrets has a greater impact on adjustment than disclosure does. It should be noted, however, that Finkenauer et al. (2002) controlled for self-disclosure, which should involve personal information that is more likely to be important, and still found that secrecy contributed to maladjustment above and beyond self-disclosure, whereas disclosure was not associated with adjustment when secrecy was taken into account. Thus, although the type of information that is disclosed or concealed may play a role in determining their effects, it cannot provide a full explanation.

Our findings may help to explain why parental knowledge and parents' efforts at acquiring this knowledge are generally not found to be predictive of adolescent adjustment when adolescent disclosure is taken into account. Measures of parental knowledge tap what parents know about their children, and this information may come mainly from adolescents' disclosure to parents (cf. Kerr \& Stattin, 2000; Stattin \& Kerr, 2000). But it may be a poor measure of what they do not know, especially of what they do not know because their children are actively concealing it from them. Parental efforts like solicitation and control may be experienced by adolescents as privacy invasion (Hawk, Hale, Raaijmakers, \& Meeus, 2008), and may thus backfire and lead adolescents to increasingly conceal information from their parents. Given the current result that secrecy seems to be the driving force behind the disclosure-adjustment link, investigations of adolescents' willingness to disclose to parents would do well to focus on secrecy instead of, or at least in addition to, disclosure.

\section{Limitations and suggestions for future research}

Our study's four-wave longitudinal design and large sample of adolescents add strength to its findings. It does, however, have its limitations. All of our measures were self-reports, and although such reports on delinquent activities and depressive feelings are considered important and reasonably reliable (e.g., Jolliffe et al., 2003; Verhulst \& Ende, 1992), and may be the only reliable means of assessing secrecy, the inclusion of multiple informants would have strengthened our study.

Because we focused our examination on Kerr and Stattin's (2000; Stattin \& Kerr, 2000) adolescent disclosure measure, we ended up with only two items in our secrecy measure, which may undermine its reliability. However, the factor loadings of the secrecy items were good, and they were highly correlated with one another and relatively uncorrelated with all other items (Tabachnick \& Fidell, 2001). Furthermore, although we conducted confirmatory factor analyses, we could not test the associations of disclosure and secrecy with adjustment in a model with these Latent factors because of insufficient sample 
size. However, given the time invariant factorial structure, our cross-lagged models using observed values of disclosure and secrecy should provide a reliable picture.

There are alternative explanations of our results that we cannot fully exclude. First, reverse coding of the secrecy items (as compared to the disclosure items) and associated differences in means (and variances) could be suggested to have given rise to our two-factor structure. Although it is possible that reverse coding played some role in yielding the two-factor structure, the external validation of the two factors in terms of their differential longitudinal links with both depression and delinquency makes it unlikely that reverse coding underlies the current findings. Second, the content of the secrecy items differs from that of the disclosure items in that the former refer to free time, whereas the latter are more focused on the school context. Studies by Smetana and colleagues (Smetana et al., 2006, 2010) have shown that secrecy and disclosure vary across peer, school, and personal domains. Therefore, we cannot rule out that differences in item content may have contributed to the two-factor structure and may partly account for the differential effects of secrecy and disclosure. Future studies may extend our knowledge by examining the associations of secrecy and disclosure in different domains. Where the current study shows that secrecy and disclosure are differentially related to adolescent adjustment, such studies may similarly show that information management is differentially related to adolescent adjustment across different domains. Indeed, a recent study by Smetana et al. (2010) made some initial headway by showing that adolescents' reasons for information management vary across domains and that secret-keeping strategies are differentially associated with depressed mood across domains.

Although we investigated the associations of disclosure and secrecy with externalizing and internalizing problems and found that only secrecy was a longitudinal predictor of both, we did not investigate the mechanism underlying this secrecymaladjustment link. We have made a number of suggestions for possible explanations of the link, but future research will have to determine its underlying causes. Our examination further focused on disclosure and secrecy from parents, but adolescents may well share some of the secrets they keep from their parents with their friends. As the impact of keeping secrets may likely depend on from whom they are kept and with whom they are shared (cf. Kelly \& McKillop, 1996), this may affect the consequences of secrecy.

Despite these shortcomings, our study provides clear evidence that disclosure and secrecy are distinct constructs that are differentially linked to adolescent externalizing and internalizing problem behavior. This evidence sheds new light on the disclosure-adjustment link, suggesting that secrecy, not disclosure, is the driving force behind this link. As such, the current results may help to shape future investigations of adolescent information management and adjustment.

\section{References}

Baerveldt, C., Rossem van, R., \& Vermande, M. (2003). Pupils' delinquency and their social networks: a test of some network assumptions of the ability and inability models of delinquency. The Netherlands Journal of Social Sciences, 39, 107-125.

Baumeister, R. F., Bratslavsky, E., Finkenauer, C., \& Vohs, K. D. (2001). Bad is stronger than good. Review of General Psychology, 5, 323-370.

Bok, S. (1989). Secrets: On the ethics of concealment and revelation. New York: Vintage Books.

Buhrmester, D. (1990). Intimacy of friendship, interpersonal competence, and adjustment during preadolescence and adolescence. Child Development, 61, $1101-1111$.

Buhrmester, D., \& Prager, K. (1995). Patterns and functions of self-disclosure during childhood and adolescence. In K. Rotenberg (Ed.), Disclosure processes in children and adolescents (pp. 10-56). New York: Cambridge University Press.

Chelune, G. J., Waring, E. M., Vosk, B. N., Sultan, F. E., \& Odgen, J. K. (1984). Self-disclosure and its relationship to marital intimacy. Journal of Clinical Psychology, 40, 216-219.

Cotterell, J. (1996). Social networks and social influences in adolescence. Florence, KY: Taylor and Francis/Routledge.

Craighead, W. E., Smucker, M. R., Craighead, L. W., \& Ilardi, S. S. (1998). Factor analysis of the Children's Depression Inventory in a community sample. Psychological Assessment, 10, 156-165.

Enders, C. K., \& Bandalos, D. L. (2001). The relative performance of full information maximum likelihood estimation for missing data in structural equation models. Structural Equation Modeling, 8, 430-457.

Finkenauer, C., Engels, R. C. M. E., \& Meeus, W. (2002). Keeping secrets from parents: advantages and disadvantages of secrecy in adolescence. Journal of Youth and Adolescence, 31,123-136.

Finkenauer, C., Engels, R., \& Kubacka, K. (2008). Relational implications of secrecy and concealment in parent-adolescent relationships. In M. Kerr, H. Stattin, \& R. Engels (Eds.), What can parents do? New insights into the role of parents in adolescent problem behavior. West Sussex, UK: John Wiley \& Sons.

Finkenauer, C., Frijns, T., Engels, R. C. M. E., \& Kerkhof, P. (2005). Perceiving concealment in relationships between parents and adolescents: links with parental behavior. Personal Relationships, 12, 387-406.

Finkenauer, C., \& Hazam, H. (2000). Disclosure and secrecy in marriage: do both contribute to marital satisfaction? Journal of Social and Personal Relationships, $17,245-263$.

Finkenauer, C., \& Rimé, B. (1998a). Keeping emotional memories secret: health and well-being when emotions are not shared. Journal of Health Psychology, $3,47-58$

Finkenauer, C., \& Rimé, B. (1998b). Socially shared emotional experiences vs. emotional experiences kept secret: differential characteristics and consequences. Journal of Social and Clinical Psychology, 17, 295-318.

Francis, M. E., \& Pennebaker, J. W. (1992). Putting stress into words: the impact of writing on physiological, absentee, and self-reported emotional wellbeing measures. American Journal of Health Promotion, 6, 280-287.

Frijns, T., \& Finkenauer, C. (2009). Longitudinal associations between keeping a secret and psychosocial adjustment in adolescence. International Journal of Behavioral Development, 33, 145-154.

Frijns, T., Finkenauer, C., Vermulst, A. A., \& Engels, R. C. M. E. (2005). Keeping secrets from parents: longitudinal associations of secrecy in adolescence. Journal of Youth and Adolescence, 34, 137-148.

Greenberg, M. A., Wortman, C. B., \& Stone, A. A. (1996). Emotional expression and physical health: revising traumatic memories or fostering self-regulation. Journal of Personality and Social Psychology, 71, 588-602.

Guerrero, L. K., \& Afifi, W. A. (1995). What parents don't know: topic avoidance in parent-child relationships. In T. J. Socha, G. H. Stamp, \& H. Glen (Eds.), Parents, children, and communication: Frontiers of theory and research. LEA's communication series (pp. 219-245). Hillsdale, NJ, England: Erlbaum.

Hartup, W. W. (1996). The company they keep: friendships and their developmental significance. Child Development, 67, 1-13.

Hawk, S. T., Hale, W. W., III, Raaijmakers, Q. A. W., \& Meeus, W. (2008). Adolescents' perceptions of privacy invasion in reaction to parental solicitation and control. Journal of Early Adolescence, 28, 583-608. 
Ichiyama, M. A., Colbert, D., Laramore, H., Heim, M., Carone, K., \& Schmidt, J. (1993). Self-concealment and correlates of adjustment in college students. Journal of College Student Psychotherapy, 7, 55-68.

Jolliffe, D., Farrington, D. P., Hawkins, J. D., Catalano, R. F., Hill, K. G., \& Kosterman, R. (2003). Predictive, concurrent, prospective and retrospective validity of self-reported delinquency. Criminal Behaviour and Mental Health, 13, 179-197.

Kahn, J. H., \& Hessling, R. M. (2001). Measuring the tendency to conceal versus disclose psychological distress. Journal of Clinical Psychology, 20, 41-65.

Keijsers, L., Branje, S. J. T., Van der Valk, I. E., \& Meeus, W. (in press). Reciprocal effects between parental solicitation, parental control, adolescent disclosure, and adolescent delinquency. Journal of Research on Adolescence.

Keijsers, L., Frijns, T., Branje, S. J. T., \& Meeus, W. (in press). Developmental links of adolescent disclosure parental solicitation and control with delinquency: moderation by parental support. Developmental Psychology, doi: 10.1037/a0016693.

Kelly, A. E., \& Achter, J. A. (1995). Self-concealment and attitudes toward counseling in university students. Journal of Counseling Psychology, 42, 40-46.

Kelly, A. E., \& McKillop, K. J. (1996). Consequences of revealing personal secrets. Psychological Bulletin, 120, 450-465.

Kerr, M., \& Stattin, H. (2000). What parents know, how they know it, and several forms of adolescent adjustment: further support for a reinterpretation of monitoring. Developmental Psychology, 36, 366-380.

Kerr, M., \& Stattin, H. (2003). Parenting of adolescents: action or reaction? In A. Booth, \& A. C. Crouter (Eds.), Children's influence on family dynamics: The neglected side of family relationships (pp. 121-151) Mahwah, NJ: Lawrence Erlbaum Associates.

Lane, D. J., \& Wegner, D. M. (1995). The cognitive consequences of secrecy. Journal of Personality and Social Psychology, 69, 237-253.

Larson, D. G., \& Chastain, R. L. (1990). Self-concealment: conceptualization, measurement, and health implications. Journal of Social and Clinical Psychology, 9 , 439-455.

Little, R. J. A. (1988). A test of missing completely at random for multivariate data with missing values. Journal of the American Statistical Association, 83, $1198-1202$.

Little, R. J. A., \& Rubin, D. B. (2002). Statistical analysis with missing data. Hoboken, NJ: Wiley.

Marshall, S. K., Tilton-Weaver, L. C., \& Bosdet, L. (2005). Information management: considering adolescents' regulation of parental knowledge. Journal of Adolescence, 22, 633-647.

Masten, A. S., \& Coatsworth, J. D. (1998). The development of competence in favorable and unfavorable environments: lessons from research on successful children. American Psychologist, 53, 205-220.

Meeus, W., Akse, J., Branje, S., ter Bogt, T., Delsing, M., \& Doorn, M. (2004). Codebook of the research project Conflicts And Managment Of Relationships (CONAMORE). Utrecht, the Netherlands: Utrecht University, Faculty of Social Sciences.

Muthen, B. O., \& Muthen, L. K. (2006). Mplus user's guide (4th ed.). Los Angeles, CA: Muthen \& Muthen.

Newth, S., \& Rachman, S. (2001). The concealment of obsessions. Behaviour Research and Therapy, 39, 457-464.

Pennebaker, J. W. (1989). Confession, inhibition, and disease. In L. Berkowitz (Ed.), Advances in experimental social psychology, Vol. 22 (pp. 211-244). New York: Academic Press.

Pennebaker, J. W. (1990). Opening up: The healing powers of confiding in others. New York: Morrow.

Pennebaker, J. W. (1997). Writing about emotional experiences as a therapeutic process. Psychological Science, 8, $162-166$.

Pennebaker, J. W., Colder, M., \& Sharp, L. K. (1990). Accelerating the coping process. Journal of Personality and Social Psychology, $58,528-537$.

Pennebaker, J. W., \& Susman, J. R. (1988). Disclosure of traumas and psychosomatic processes. Social Science and Medicine, $26,327-332$.

Pennebaker, J. W., Zech, E., \& Rimé, B. (2001). Disclosing and sharing emotion: psychological, social, and health consequences. In M. S. Stroebe, R. O. Hansson, W. Stroebe, \& H. Schut (Eds.), Handbook of bereavement research: Consequences, coping, and care. Washington, DC: American Psychological Association.

Petrie, K. J., Booth, R. J., Pennebaker, J. W., Davison, K. P., \& Thomas, M. G. (1995). Disclosure of trauma and immune response to a hepatitis B vaccination program. Journal of Consulting and Clinical Psychology, 63, 787-792.

Satorra, A., \& Bentler, P. M. (1994). Corrections to test statistics and standard errors in covariance structure analysis. In A. von Eye, \& C. C. Clogg (Eds.), Latent variables analysis: Applications for developmental research (pp. 399-419). Thousand Oaks, CA: Sage Publications.

Satorra, A., \& Bentler, P. M. (2001). A scaled difference chi-square test statistic for moment structure analysis. Psychometrika, 66, 507-514.

Smetana, J. G. (2008). "It's 10 o'clock: do you know where your children are?" Recent advances in understanding parental monitoring and adolescents' information management. Child Development Perspectives, 2, 19-25.

Smetana, J. G., Metzger, A., Gettman, D. C., \& Campione-Barr, N. (2006). Disclosure and secrecy in adolescent-parent relationships. Child Development, 77, 201-217.

Smetana, J. G., Villalobos, M., Rogge, R. D., \& Tasopoulos-Chan, M. (2010). Keeping secrets from parents: Daily variations among poor, urban adolescents. Journal of Adolescence, 33(2), 321-331.

Smyth, J. M. (1998). Written emotional expression: effect sizes, outcome types, and moderating variables. Journal of Consulting and Clinical Psychology, 66, $174-184$.

Soenens, B., Vansteenkiste, M., Luyckx, K., \& Goossens, L. (2006). Parenting and adolescent problem behavior: an integrated model with adolescent selfdisclosure and perceived parental knowledge as intervening variables. Developmental Psychology, 42, 305-318.

Stattin, H., \& Kerr, M. (2000). Parental monitoring: a reinterpretation. Child Development, 71, 1072-1085.

Tabachnick, B. G., \& Fidell, L. S. (2001). Using multivariate statistics. Boston: Allyn \& Bacon.

Verhulst, F. C., \& Ende, J.van der (1992). Agreement between parents' reports and adolescents' self-reports of problem behavior. Journal of Child Psychology and Psychiatry, 33, 1011-1023.

Waizenhofer, R. N., Buchanan, C. M., \& Jackson-Newsom, J. (2004). Mothers' and fathers' knowledge of adolescents' daily activities: its sources and its links with adolescent adjustment. Journal of Family Psychology, 18, 348-360.

Wegner, D. M., \& Lane, J. D. (1995). From secrecy to psychopathology. In J. W. Pennebaker (Ed.), Emotion, disclosure, and health (pp. 25-46). Washington, DC: American Psychological Association. 